\title{
İhracatın Finansmanında Şer’i Kurallara Uygun Alternatif Yaklaşım; Türkiye Örneği
}

\author{
Serdar KUZU ${ }^{1 *}$, Hakan BEROĞLU ${ }^{2}$, Halil ARSLAN ${ }^{3}$, Temur KAYHAN ${ }^{4}$, Seyit Ali EREN ${ }^{5}$ \\ ${ }^{1}$ Dr. Öğr. Üyesi, İstanbul Üniversitesi, Muhasebe ve Vergi Bölümü, orcid id: 0000-0001-8178-8749 \\ ${ }^{2}$ Dr., Investrade Portföy Yönetimi A.Ş., orcid id: 0000-0002-7231-3503 \\ ${ }^{3}$ Dr., İstanbul Şehir Üniversitesi, İşletme Fakültesi, orcid id: 0000-0003-0853-0244 \\ ${ }^{4}$ Dr., İstanbul Şehir Üniversitesi, İşletme Fakültesi, orcid id: 0000-0003-3738-2025 \\ ${ }^{5}$ Öğr. Gör., İstanbul Üniversitesi, İşletme Yönetimi Bölümü, orcid id: 0000-0001-5707-5941
}

Geliş Tarihi/Received: 08.08.2018

Kabul Tarihi/Accepted: 17.09.2018

Araştırma Makalesi/Research Article

\section{ÖZET}

Türkiye ekonomi modelinin önümüzde yıllarda yapılacak reformlarla ihracat odaklı büyümeye yakınsayacağı aşikardır. Bu yapılmadığı takdirde cari açığın yarattı̆̆ı risklerle dalgalı ekonomi süreci devam edecektir. Çalışmamızın odak noktası söz konusu planın bir parçası olarak büyüme potansiyeli olan ancak hem Banka hem de Eximbank’ta limiti dolmuş şirketler için borçlanmadan ve bankacılı̆̆ı aradan çıkartarak ihracat finansmanın nasıl sağlanacağı üzerindedir. Ayrıca sukuk modelinde Türkiye'de sınırlı sayıda ve ortalama 5 yıl vadede olan dolar sukukları için miktarı önemli oranda artığı gözlemlenmektedir. Bununla birlikte ürünün banka modelini Ortadoğu'da kullanan yatırımcılar için sukuk modeli ile menkul kıymetleştirme sağlanmaktadır. Ülkemizde SPK kontrolü altında yapılacak ihraç, güveni artıracağı gibi menkul kıymetleştirme vade öncesi çıkışı beraberinde getirecektir. Ürünün alacak sigortalı olması da ikincil piyasada likiditeyi artıracaktır. Bunun sonucunda geleneksel anlamda Ortadoğu'da ürünü kullanan yatırımcılar için sukuk modeli daha cazip olacak ve Türkiye’ye körfez sermayesinin akışını artıracaktır.

Anahtar kelimeler: Sukuk, İhracat, Ticaretin Finansmanı, Yatırımcılar, Körfez Sermayesi.

* Sorumlu yazar/Corresponding author

E-mail/e-ileti: serdar.kuzu@istanbul.edu.tr 


\title{
Alternative Approach to Shar'i Rules in Export Financing; The Case of Turkey
}

\begin{abstract}
It is obvious that the model of Turkey's economy will be closer to export oriented functioning structure with the help of coming structural reforms. If this is not done, the fluctuating economy process will continue with the risks created by the current account deficit. The focus of our work is on how to provide export financing for the companies that have the potential of growth but do no have ability to raise funds from both the conventional, participation banks and the Eximbank. Also it is also almost certain that the sukuk model which we have constructed for export financing will increase the issued amount of USD based lease certificates and will allow the maturities to be shorter than usual. Thus, securitization is provided by the sukuk model for investors who use the product bank model in the Middle East. The fact that the product is insured will increase the liquidity in the secondary market. As a result, in the traditional sense sukuk model for investors using the product will be more attractive in the Middle East and the Gulf region and this attraction will increase the flow of capital to Turkey.
\end{abstract}

Keywords: Sukuk, Export, Trade Finance, Investors, Gulf Capital.

\section{GÍRİŞ}

Son dönemde Türkiye'nin büyüme modelinin ihracattan ziyade iç tüketime dayanması önemli eleştiri alan bir konu haline gelmiştir. Bu durum ihracata dayalı büyüme modellerinin incelenmesini beraberinde getirmektedir. Dünyada artan faizler ve bankalarda likiditenin azalması ise ihracat finansmanının önünü tıkayan yeni değişkenler olarak karşımıza çıkmaktadır. Büyüme potansiyeli bulunan ancak banka limiti dolmuş ya da bankalarda likidite azaldığı için işletme sermayesi anlamında fon bulamadığı için büyüme potansiyeli azalmış ihracat firmalarının finansmanı ön plana çıkmaktadır.

İhracat odaklı ticaretin finansmanı için literatürde farklı uygulamalar görülmüştür. Akreditif bunlardan en yaygın olanıdır. Makalede anlatılan 2 adımlı mudaraba modeli ise akreditife bir alternatif oluşturacaktır. Model firmaların bankalardaki limitini aşındırmadan ihracatın finansmanını sağlamaktadır. Ayrıca modelin ikinci kurgusu olan sukuk senaryosunda ise model menkul kıymetleşmekte ve bankacılık modeline göre daha likit bir alternatif oluşturmaktadır. İkinci model sadece ihracat finansmanı sağlamamakta ayrıca 
Ortadoğu'da yaygın bir şekilde kullanılan ancak menkul kıymetleşmediği için likit olmayan bankacılık kurgusuna göre daha likit bir senaryo olduğu için Ortadoğu'da ürün için gerçekleştirilen yatırımların da Türkiye'ye akmasını beraberinde getirebilir.

Kurguladığımız model, hem pratikte uygulanabilir olması hem de ihracata dayalı büyümeyi teşvik etmesiyle mevcut büyüme modelinden kaynaklanan problemlere çözümler sunmaktadır. Bununla birlikte körfezdeki sermayenin döviz ihtiyacının arttığı bir dönemde Türkiye'ye gelmesini de beraberinde getirebilir. Çalışmamız literatürdeki birçok uygulamaya göre daha pratik öneriler sağlayacaktır. Akademik ve teorik bir çalışma olarak kalmaktan ziyade resmi otorite ve işleticilere önemli çıkış noktaları sunmaktadır. Makalenin hazırlanmasında sadece literatür taraması yapılmamış, yurtdışı yatırımcılar, Türkiye'deki katılım bankaları, modeli işletebilecek işletmeciler ve Eximbank ile görüşmeler yapılmıştır. Makalemizin ikinci bölümünde literatürdeki çalışmalar incelenecek; üçüncü bölümünde modelin kurgusu anlatılacak, son bölümde ise modelin kolaylıkları ve karşılaşabileceği zorluklar siralanacaktır.

\section{LITERATÜR TARAMASI}

Günümüz dünyasında ülkelerin en önemli hedefleri arasında istikrarlı bir büyüme, düşük işsizlik oranları, yüksek refah seviyesi, öngörülebilir ve volatilitesi düşük fiyat seviyeleri bulunmaktadır. Bu hedeflere ulaşılabilmesi için ülkelerin ekonomi bakanlıkları ülkenin bulunduğu ekonomik koşullara göre mali politikalar geliştirirken merkez bankaları ise para politikaları ile ekonomiye yön vermeye çalışmakta ve volatiliteyi azaltıp öngörülebilirliği artırmaya çalışmaktadırlar.

Ekonomilerin büyümesi ve düşük işsizlik rakamları gibi hedeflere ulaşılması karşısındaki en önemli engellerden biri şirketlerin fon kaynaklarına yeterince ulaşıp ulaşamadığı sorunudur. Nitekim 2008 global krizinde var olan finansal risklerin şirketlere hatta ülkelere nasıl dağıldığı tam olarak tespit edilememesi ve Fannie Mae ve Freddie Mac gibi mortgage şirketlerinin iflas etmesi ile artan tedirginlik ve stress kredi mekanizmasını sekteye uğratmıştır. Kredi mekanizmalarının bozulması şirketlerin fon kaynaklarına ulaşmasını engellemiş ve dolayısıyla üretim ve tüketim azalıp işsizlik önemli oranda artış kaydetmiştir.

2008 global finansal krizinin gerçekleşmesine sebep olan faktörlerden iki tanesi bankaların genellikle değişken getiri oranına sahip ipotekli mortgage kredilerini normalde 
krediyi geri ödemesi mümkün olmayabilecek riskli kategorideki müşterilere vermesi ve bu kredileri menkul kıymetleştirerek özel sektör yatırımcılarına satmaları olarak gösterilebilir. (Abdul Aziz \& Gintzburger, 2009, s. 270-278). Mortgage kredilerinin getirilerinin genellikle değişken oranlı olması söz konusu kredilerin menkul kıymetleştirilerek özel sektöre daha kolay pazarlanabilmesine olanak sağlamıştır. Pazarlanabilmesinde diğer bir etken ise bu ürünlerin menkul kıymetleştirilmesi ile ikincil piyasada işlem görebilmeleridir. İkincil piyasada işlem görebilmeleri ve olası faiz artışlarına karşı değişken oranlı getiri sunmaları nedeni ile özel sektör yatırımcıları ve özellikle de emeklilik fonları tarafından oldukça ilgi görmüşlerdir. Şer'i kanunlara göre ise ortada bir varlık olmadan alacağın menkul kıymetleştirilmesi mümkün olmadığı gibi değişken getiriye sahip finansman sağlamak ve menkul kıymetleştirilen alacak veya borçların ikincil piyasada işlem görmesi mümkün değildir. Değişken getiri karşı taraf için negatif anlamda belirsizlik taşıması nedeniyle şeri kurallara uygun değildir ve bu olumsuz belirsizlik durumu "Garar" olarak adlandırılmaktadır. Alacakların ya da borçların menkul kıymetleştirilerek satılması ise Arapça'da "Bai Al Dayn" olarak ifade edilmekle birlikte bunların ikincil piyasada işlem görmesi mümkün değildir. $\mathrm{Bu}$ ve benzeri prensiplerinden dolayı İslami finansın 2008 benzeri finansal krizlere karşı doğal bir izolasyona ve bağışıklık mekanizmasına sahip olduğuna inanılmaktadır. Bununla birlikte globalleşmenin etkisi ile İslam ülkeleri kendilerini global finansal krizin etkilerinden kurtaramamışlardır (Singh, 2009).

Konvansiyonel finansman yöntemleri ile ticaretin ya da yatırımın finansmanı sağlanabilmektedir. Söz konusu finansman sağlanırken krediyi sağlayan kurumlar ile borç alan kurumlar arasında bir borç alacak ilişkisi doğmakta ve bu ilişkinin sonunda ticaretin ya da yatırımın karlılık durumuna bakılmaksızın krediyi sağlayan taraf, krediyi alan taraftan finansmanın sağlanması aşamasında belirlenmiş pozitif bir getiri talep etmektedir. Bu getiri tutarı İslam bilginleri tarafından haram kabul edilmiş ve faiz yani Arapça'da "riba" olarak tanımlanmıştır (Iqbal \& Tsubota, Emerging Islamic Capital Markets, 2006, s. 5-11), (Iqbal \& Mirakhor, 2006), (Iqbal \& Llewellyn, 2000).

İslami finansman ise konvansiyonel finansman türünden bazı noktalarda ayrılmaktadır. Ayrımı sağlayan en önemli noktalar finansman sağlayan ile finansmana ihtiyacı olan taraf arasındaki ilişkinin boyutu ve faizin finansman yapılandırmasında yapıdan tamamen çıkarılmasıdır. Faizin yapıdan çıkarılması ise finansman sağlayan tarafın riski ve getiriyi paylaşması ile sağlanmıştır. Diğer bir ifade ile finansmana konu varlık, iş ya da hizmet karlılığı ölçüsünde finansman sağlayan tarafa getiri vaat etmektedir. Aksi yani zarar 
durumunda ise finansman sağlayan taraf herhangi bir getiri talep edemeyeceğini kabul etmektedir.

Ticaret ve yatırım alanlarında ihtiyacı olan kurumlara finansman sağlayabilmek adına çeşitli İslami finansal ürünler geliştirilmiştir. Bu ürünler kurgulanırken şeri kurallara aykırılık teşkil etmemesi için getiri, faizden değil riskin ve karın paylaşımından elde edilmektedir. İslami finansal ürünlerde karşı taraf için negatif anlamda bir belirsizlik oluşturabilecek ya da spekülasyon ve kumar olabilecek tüm oluşumlar yasaklanmakta ve ürünler kurgulanırken bu prensiplere uyulmaktadır. Belirsizlik kaynağı olabilecek durumlar üründen izale edilmektedir. Ayrıca İslami olarak haram kabul edilen tüm faaliyet alanları için söz konusu İslami finans ürünleri finansman sağlama anlamında kullanılmamaktadır.

İslami finans ürünlerini üç ana kategoriye ayırabiliriz; varlık tabanlı finansman, sermaye tabanlı finansman ve hizmet, iş tabanlı finansman (Gundogdu \& Dogan, 2014, s. 268-285), (Abdul Aziz \& Gintzburger, 2009, s. 270-278). Her bir kategoride taraflar arasındaki anlaşmanın yapısı ile finansman sağlayan taraf ile finansmana ihtiyacı olan taraf arasındaki ilişki farklılık gösterebilmektedir. Varlığa dayalı finansman türünde müşteri tarafindan alınmak istenen varlık bir banka ya da finans kurumu tarafından satın alınır ve aynı anda başta anlaşılan bir kar oranı ile müşteriye satılır. Banka'nın bu işlemdeki karı alım satım fiyatı arasındaki fark kadardır ve müşteri borcun geri ödemelerini başta anlaşılan tarihlerde vadeli olarak gerçekleştirir. Bu tarz finansman yönteminde banka ile müşteri arasındaki ilişki alıcı ve satıcı arasındaki ilişki tarzındadır ve bu işlemlere "Murabaha" işlemleri denilmektedir. Konvansiyonel finansman yöntemlerinde ise bu durum borç alacak ilişkisi şeklinde temellendirilir (Gundogdu, 2016, s. 78-92) .Sermaye tabanlı finansmanda ise banka girişime sermaye sağlarken müşteri de girişimle amaçlanan faaliyete yönelik iş bilgisini ortaya koyar. Müşterinin banka gibi girişime iş bilgisinin yanı sıra sermaye koyması da mümkündür. $\mathrm{Bu}$ finansman türünde banka ile müşteri arasındaki ilişkinin mahiyeti ortaklık ilişkisidir. Girişimin elde edeceği kar başta anlaşılan oranlarda banka ve müşteri arasında paylaşılır. Girişimin nasıl sonlandırılacağına dair tüm kararlar henüz faaliyete geçmeden, sermaye enjeksiyonu yapılmadan müşteri ve banka arasında karara bağlanmıştır. Olası bir zarar durumunda ise her iki tarafta koydukları sermaye tutarında zarara ortaktırlar. Bu tarz bir yapı ile gerçekleştirilen finansmana ise "Musharaka" adı verilmektedir. Üçüncü bir finansman yönteminde ise bir hizmetin ya da bir işin finansmanı sağlanır. Bu duruma en açık örnek leasing işlemleridir. Müşterinin leasing ile kendi bünyesine katmak istediği varlık banka tarafından satın alınır ve müşteriye kiralanır. Vade sonunda ise müşterinin varlığı satın 
alma opsiyonu bulunmaktadır. Konvansiyonel kirala-satın al anlaşmaları ile benzer niteliktedir. Buradaki finansman işleminde banka ile müşteri arasındaki ilişkinin boyutu kiralayan-kiracı formatındadır. $\mathrm{Bu}$ işlem için yapılan finansmana "ijara wa-iqtina" denilmektedir.

Türkiye gibi cari açık veren, enerjide dışa bağımlı, gerek ihracat gerekse yurtiçi tüketim için yapılan üretimlerin gerçekleşebilmesi için ara malı ithalatının yapılmasının olmazsa olmaz olduğu ülkelerde özellikle USD bazlı fon kaynaklarına duyulan ihtiyaç her dönemde yüksek olmaktadır. Söz konusu USD bazlı fon ihtiyacının giderilebilmesinde ihracatın artırılması önemli katkı sağlayacaktır. İhracatın artırılabilmesi için ise atılacak en önemli adımlardan biri şirketlerin ihracatını kolaylaştırıcı yasal düzenlemeleri hayat geçirmek ve şirketlerin ulaşabilecekleri fon kaynaklarının çeşitliliğini artırmaktır. Dünya Ticaret Örgütü'nün verilerine göre Dünya üzerindeki ticaretin \%80-90 kadarı ticaretin finansmanına bağlıdır ve genellikle ihracat yapan şirketler arasında finansmana ihtiyaç duyan şirketler özellikle küçük ve orta boy işletmelerdir (KOBİ). Ülkelerin üretiminin artmasında ve işsizliğin azalmasında KOBİ'lerin önemli oranda katkılarının olduğu bilinmektedir (Cravoy, Gourlayy, \& Beckery, 2012, s. 217-230). Ayrica (Rocha, Farazi, Khouri, \& Pearce, 2011) ve (Beck, Demirguc-Kunt, \& Levine, 2005, s. 199-229) yaptı̆̆ı çalışmada aynı sonuçlara ulaşmıştır. Bu açıdan bakıldığında KOBİ'lerin işletme sermayesi ihtiyaçlarını karşılayacak şekilde fon kaynaklarına erişimini kolaylaştırmak gerek ekonomik büyüme gerekse istihdam artışı anlamında göz ardı edilemeyecek bir öneme sahiptir. Dolayısıyla Avrupa ve Amerika'nın yanı sıra Arap ve Körfez ülkelerinden de fon temin etmek fon kaynaklarının çeşitliliğini ve tutarını artırmak adına oldukça gereklidir. Bununla birlikte Arap ve Körfez bölgelerinden fon temin edilmesi ancak İslami prensiplere uygun finansman yapılarının kurgulanması durumunda mümkün olacaktır.

$\mathrm{Bu}$ makalede üzerinde durduğumuz husus ihracat yapan şirketlerin işletme sermayesi ihtiyacını karşılamak ve böylece daha fazla ihracat yapabilmelerini sağlamak adına İslami prensiplere uygun bir yapının kurgulanmasıdır. Detayları sonraki bölümlerde anlatılmakla birlikte söz konusu finansman işlemi varlığın aynı anda finansman sağlayan kuruluş tarafından alınıp karşı tarafa vadeli olarak satılması işlemine dayanmaktadır. Karşı taraf ise vadeli olarak satın aldığı varlığı ithalat yapan firmaya vadeli olarak satacak ve vade tarihinde elde ettiği satış bedelini bankaya ödeyecektir. Bankanın bu işlemden karı alış ve satış fiyatı arasındaki fark kadardır. Dolayısıyla bu yapıda gerçekleşen "İslami Ticaret Finansmanı”, "Varlığa Dayalı Finansman” kategorisine girmektedir. Bununla birlikte finansman sağlayan 
kuruluş bir banka olmasının yanı sıra özel amaçlı kurulmuş bir şirket de (SPV) olabilir. Kurguladığımız yapıda finansmanın sağlanması için uygulanması planlanan diğer bir yol ise SPV tarafından sukuk ihracının gerçekleştirilmesi sonrası elde edilen fonlar ile ticarete konu varlığın finansmana ihtiyacı olan ihracatçı şirketten peşin olarak satın alınmasıdır. Peşin alınan varlık ithalatçı firmaya vadeli olarak satılacak ve alım satım farkı üzerinden gelir elde edilecektir. Bu sürece "taskik" adı verilmektedir. Kurgunun detayları sonraki bölümlerde anlatılacaktır.

\section{MODELINN ORTADOĞU UYGULAMALARI}

Ortadoğu'da İslami bankaların fetva kurumlarının kararları sonrası ürün geliştirilmiş ve Ortadoğu'da uygulamaya alınmıştır. Ürünün geliştirilmesi safhasında İsviçre merkezli aracı firmalar ve yurtdışı merkezli bankalar kurulmuştur. Modelin içerisinde yer alan sigorta kapsamı nedeniyle Hermes ve Coface gibi sigorta şirketleri ile sağlıklı bir iletişim sağlanmıştır.

Fetva kurullarının talebi üzerine İslami bir ürün olabilmesi içim gerekli tüm dokümantasyonlar sağlanmıştır. Yapılan ihracatın sanal bir işlem olmadığını göstermek adına ürünün teslim edildiği ve ürünün alıcısının bu ürünü ilk kontrol sonrası alacağına dair vaadini belirten fatura öncesi bir kontrol noktası belirlenmiştir. Bununla birlikte vade sonunda ithalatçının yükümlülüklerini yerine getirmemesi halinde $\% 90$ alacak sigortası için gerekli dokümantasyonlar ve süreçler tesis edilmiştir. Ortadoğu'daki İslami bankalar, bünyelerinde ürün tanımlamasını yapmışlardır. Restricted Wakala sözleşmesi tanımlanmış, müşteriler için özel havuzlar açılmış ve Business Wakala Deposit hesapları katılım hesapları şeklinde bankalarca açılmıştır.

Bu yapı mevcut hali ile Ortadoğu'da yatırımcılar ve bankalar nezdinde çalışmaktadır. Ortadoğu'daki yatırımcılar kendi bölgelerinde kurdukları yapı ile Türk şirketlerini de finanse edebilmektedirler. Son 1 yılda Türkiye'de faaliyet gösteren 450 ihracatçı 4.500 işlemde ve toplamda 1 milyar dolar yatırım ile finanse edilmiştir. Ancak ürünün ikinci el piyasası ya da menkul kıymetleştirilmesi henüz yapılmamış olup makalemizde bahsettiğimiz model ile bu süreç tanımlanmaktadır. Ayrıca Türk bankaları üzerinden modelin kurgulanması ve pratikte uygulaması henüz bulunmamaktadır. Model ile ilgili temel özellikler aşağıda Şekil 1'de yer almaktadir. 


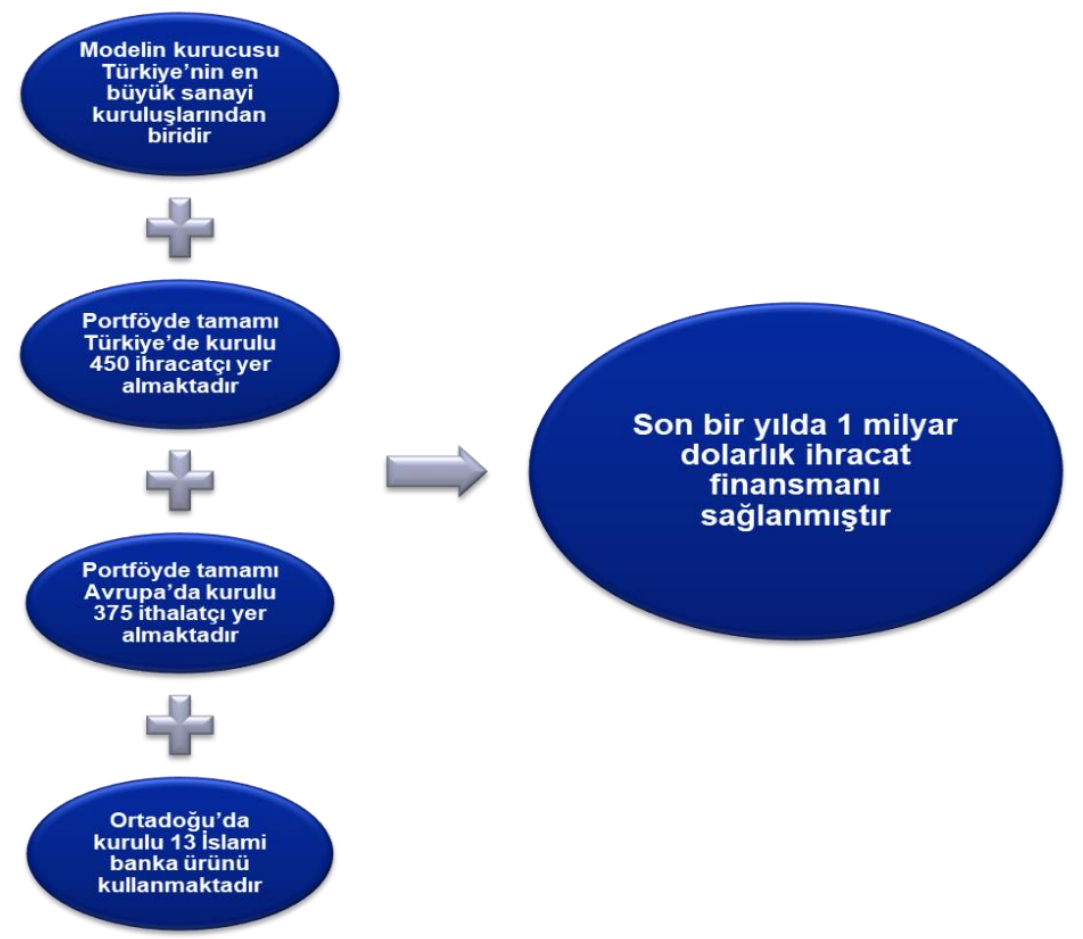

Şekil 1. Sukuk modeli temel özellikleri

\section{MEVCUT TAHVIL VE SUKUK (KİRA SERTIFİKASI) PIYYASASI}

$\mathrm{Bu}$ bölümde tahvil ve sukuk piyasası altında temel bilgiler verilecektir.

\subsection{Tahvil Piyasası}

Tahvil ihraç maliyetleri kredi maliyetlerinden daha düşük olabilmektedirler. Ayrıca tahvil ihraçları banka limitlerinin dolduğu şirketler için fonlama açısından önemli bir alternatif oluştururken geri çağırma, teminat ve ipotek gibi kredilerde yaygın bir şekilde kullanılan yapılardan aridir. Mevcut durumda borsada kote olan tahvil ihraçlarının toplam değeri yaklaşık 18,3 milyar TL olurken bu durum ortalamada \%60 borçluluk seviyesiyle faaliyetlerini devam ettiren borsa ve borsa dişı şirketleri göz önünde bulundurulduğunda ihraç tutarları için önemli bir potansiyel olduğu şeklinde yorumlanabilir. 


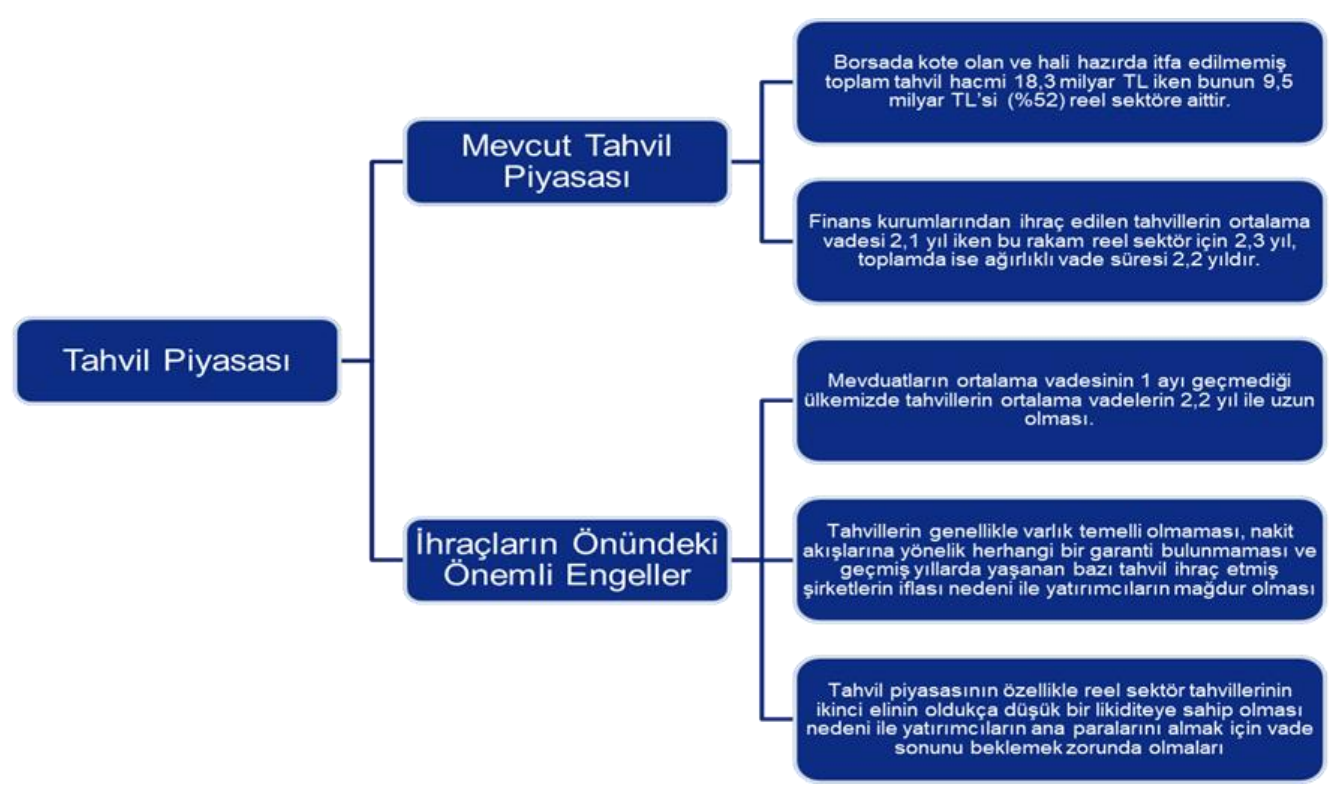

Şekil 2. Tahvil piyasası ile ilgili temel bilgiler

\subsection{Sukuk Piyasası}

USD bazlı ihraçlarda özel sektörün oranı \%47`dir. 4 milyar USD tutarındaki ihracı gerçekleştiren ise IDB Trust Services yani İslam Kalkınma Bankası'dır. Yani borsaya kote olmuş dolar bazlı sukuk piyasasında Hazine ve IDB neredeyse piyasanın tamamına sahiptir.

Ticaretin doğal akışı içerisinde gerçekleşen mal alım satımının tahvil veya kira sertifikası yolu ile uygun bir şekilde yapılandırılması hem vadeleri aşağı çekecek hem de ikinci el piyasasını aktif hale getirecektir.

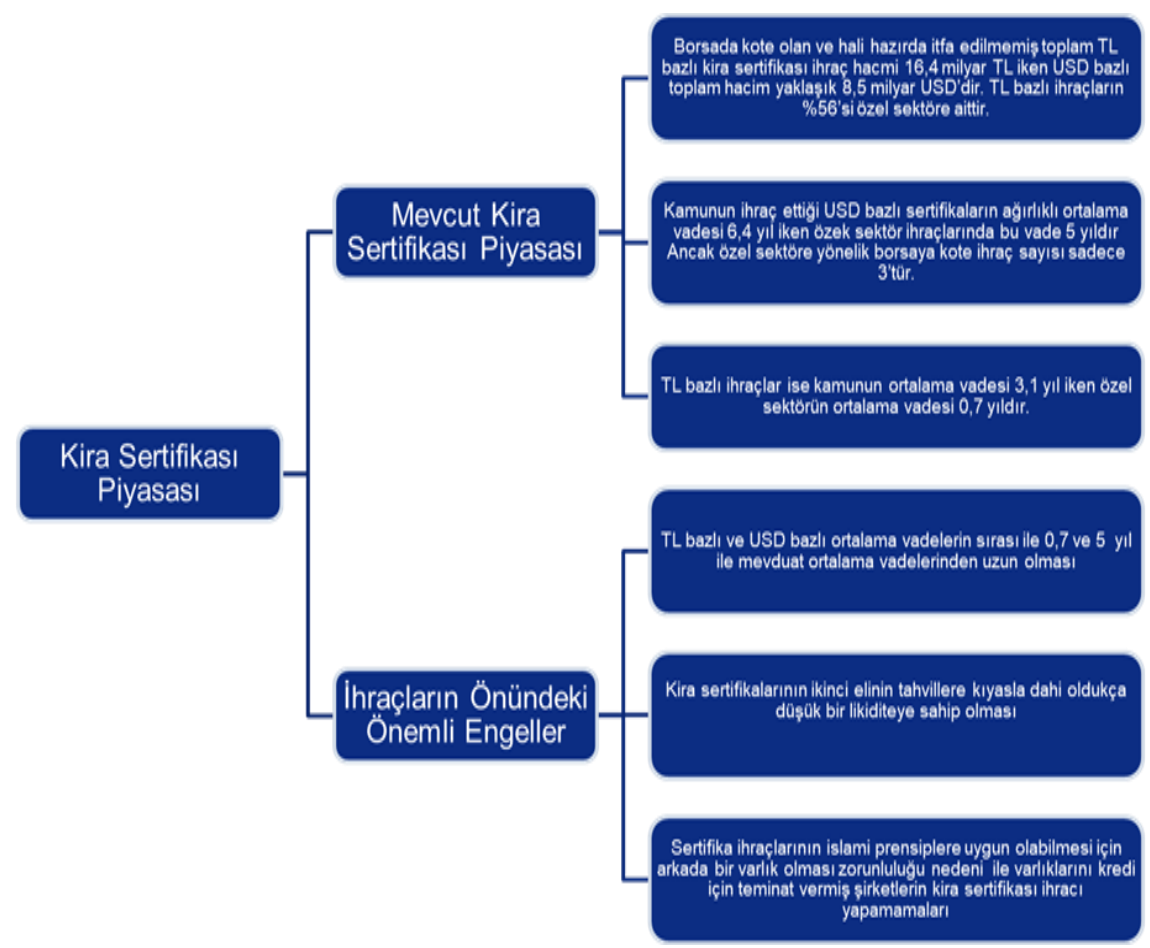

Şekil 3. Kira sertifikası piyasası ile ilgili temel bilgiler 


\section{TICARETIN FINANSMANI SUKUK MODELI}

\subsection{Mudaraba Uygulaması}

Mudaraba genel olarak taraflardan birinin sermaye diğerinin ise iş bilgisini (Knowhow) koyduğu ve elde edilen karın başta anlaşılan oranlarda hem mudarib'e hem de Rab'ul Mal'a paylaştırılmasını ifade etmektedir.

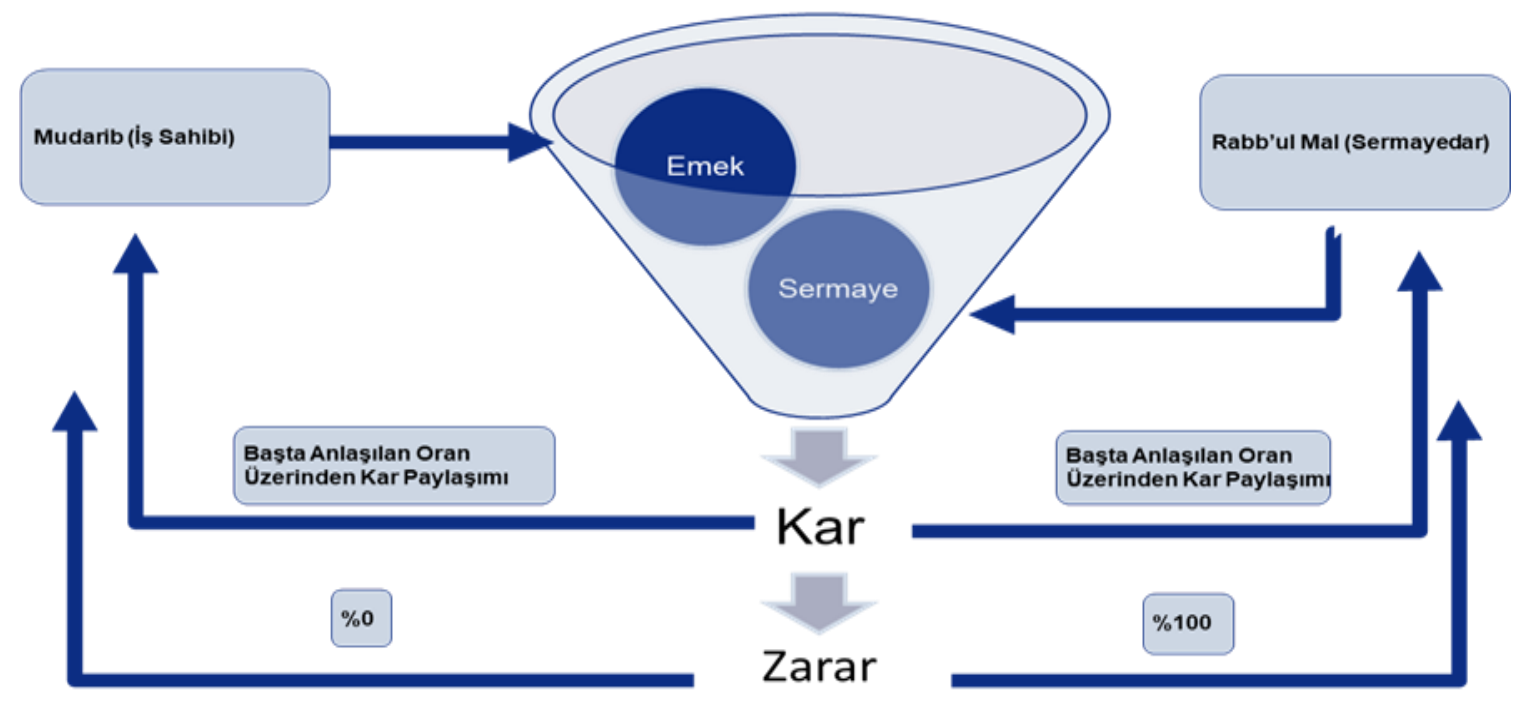

Şekil 4. Mudaraba uygulamasının işleyişi

Mudaraba kapsamında Mudarib'in fon temini iki ana yöntemle gerçekleştirilebilir; Mudarib'in yönetime dayalı kira sertifikası ihraç etmesi, PYŞ'lerin sahip oldukları fonları bir banka ile restricted mudaraba anlaşması yaparak dolaylı olarak Mudarib'e aktarması. Ticaretin finansmanı modelini Türkiye'de sukuk modelinde uygulamak istediğimizde birçok çözüm ortağına ihtiyaç duyulacaktır. Bunlar Şekil 5'te özetlenmiştir.

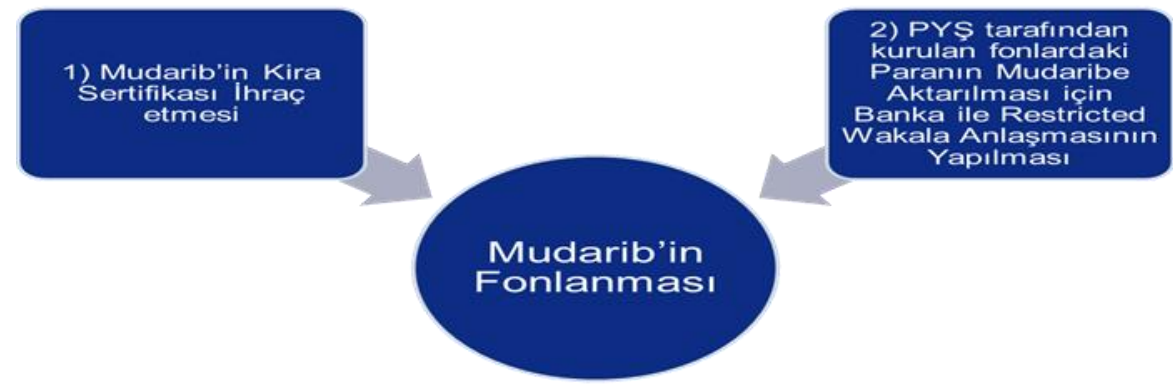

Şekil 5. Mudarib'in fon temini işleyişi 


\subsection{Genel İslami Ticaret Finansmanı Yapısı}

Ortadoğu'da uygulandığı şekilde genel İslami ticaret finansman yapısı aşağıda Şekil 6'daki gibi özetlenebilir.

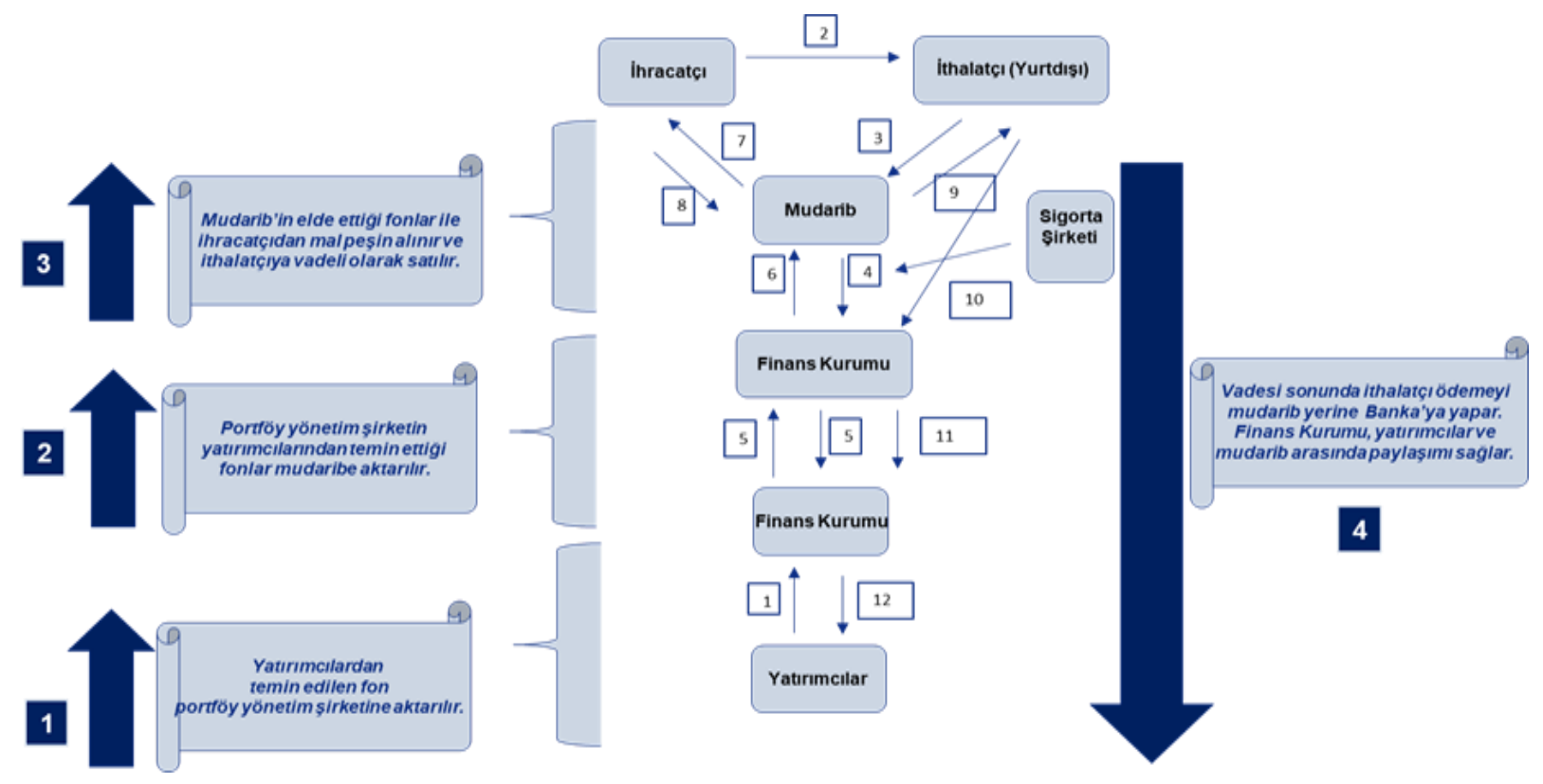

Şekil 6. İslami ticaret finansman yapısı

\section{3. İslami Ticaret Finansmanı Sukuk Kurgusu}

Mevcut hali ile İslami ticaret finansmanı sukuk modelleri üzerinden yapılmamaktadır. Önerimiz bu modelin ülkemizde uygulanması halinde dolar bazlı sukuklarda önemli bir gelişme olacağı ve mevcut vadelerin ortalama 3-5 yıldan 5-9 aya gerileyeceği gözlenecektir. İhracat finansmanına ek olarak dolar bazlı sukuklar için önemli bir hacim oluşacaktır. Bu ürün, ticaretin finansmanı modelinin menkul kıymetleşmesini beraberinde getirecek, Bankacılık dominasyonundan kurtaracak ve ikinci piyasası oluşacağı için Ortadoğu'daki birçok ticaret finansmanı yatırımcısını Türkiye'ye çekecektir.

Sermaye Piyasası Kurulu'nun (SPK) ilgili tebliğine göre yönetime dayalı kira sertifikasının (sukuk) ihracı için kaynak kuruluşun ya da ihraç edilecek ürünün yatırım yapılabilir seviyede not almış olması ya da kaynak kuruluşun kurumsal yönetim ilkelerinin 1 . ya da 2. grubuna giren halka açık ortaklık olması gerekmektedir. Mudarib'in alacakları sigorta şirketi tarafından sigortalanacağı için kira sertifikası büyük bir olasılıkla yatırım yapılabilir notu alacaktır. Aşağıda Şekil 7'de İslami Ticaret Finansmanı Sukuk Kurgusu İşleyişi yer almaktadir. 


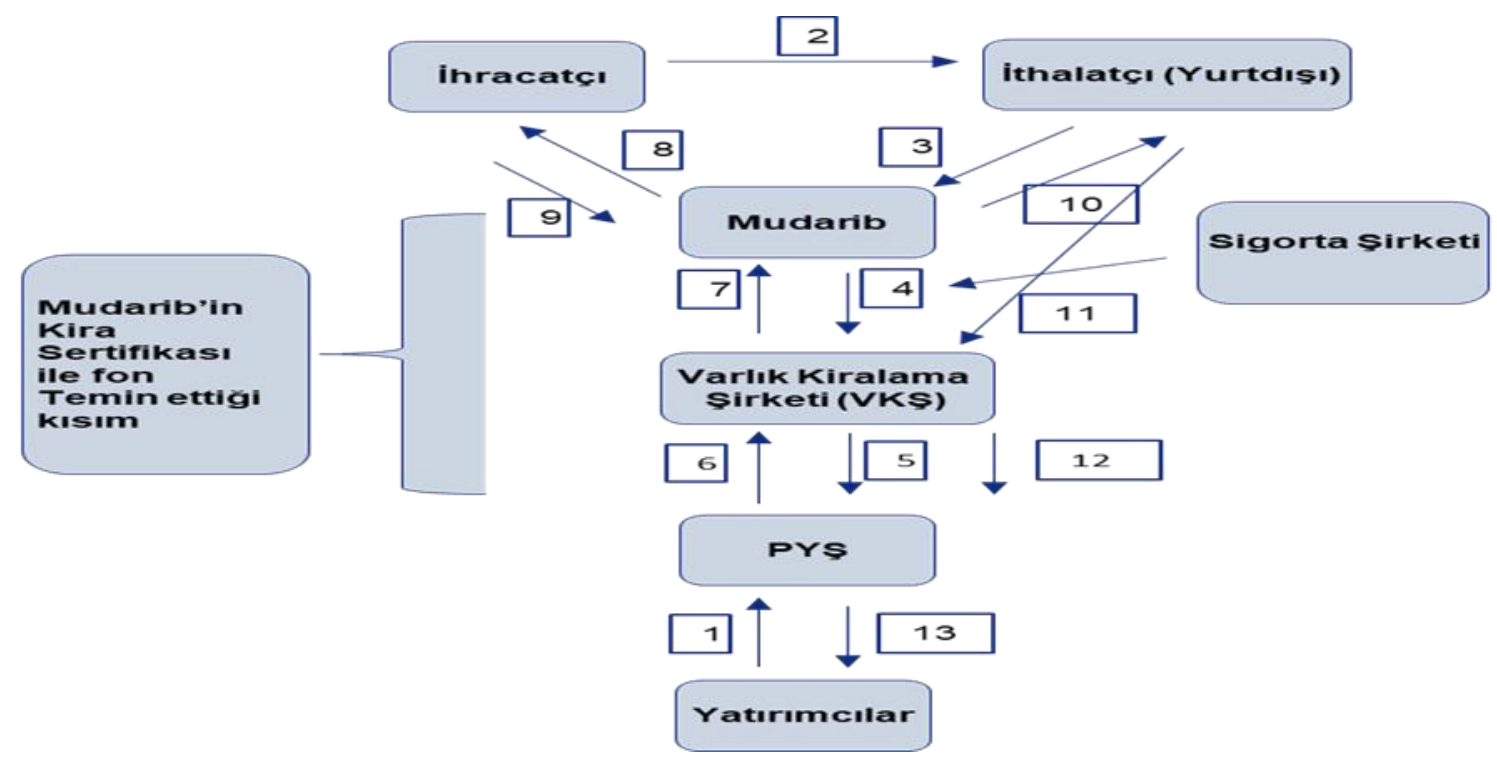

Şekil 7. İslami ticaret finansmanı sukuk kurgusu işleyişi

1) Portföy Yönetim Şirketleri (PYŞ) Türkiye'de kurduğu GSYF (Girişim Sermayesi Yatırım Fonu), Serbest fon, Sukuk Fonu ya da bireysel portföy yönetimi çerçevesinde nitelikli yatırımcilardan yatırımcılardan fon toplar.

2) İhracatçı firma ile ithalatçı firma malın satımı konusunda anlaşırlar. Ancak işlemin şer’i kurallara uygun olması için mal ithalatçıya fatura kesilmez.

3) İthalatçı firma malın uygun olduğunu kontrol ettikten sonra "Buyers Acceptance" denilen belgeyi yani malı alacağını vade sonunda parayı vereceğini belirten belgeyi Mudarib'e verir. Bu bir kontrol mekanizmasıdır ve fatura henüz kesilmemiştir.

4)Mudarib, "Buyer's Acceptance" belgesini ve alacağını sigortaladığına dair belgeyi Varlık Kiralama Şirketi’ne (VKŞ) iletir.

5) VKŞ, Buyer's Acceptance ve alacağın sigortalandığına dair belgeyi inceledikten sonra kaynak kuruluşun Mudarib olacağı yönetime dayalı kira sertifikası ihracını nitelikli yatırımcıya satar. Nitelikli yatırımcıya satışta bir aracı kurum ihtiyacı bulunmamaktadır.

6) VKŞ, PYŞ'den sertifikalar karşılığında fonları temin eder.

7) VKŞ, PYŞ’den aldığı fonları Mudarib'e aktarır.

8) Mudarib, temin ettiği fonları ihracatçıdan malı satın almak için kullanır.

9) İhracatçı bedelini peşin tahsil ettikten sonra malın mülkiyeti mudaribe geçer. 
10) Mudarib, bedelini vadesinde tahsil etmek üzere malı ithalatçıya satar.

11) İthalatçı vadesi gelince malın bedelini VKŞ'ye iletir.

12) VKŞ, ithalatçıdan tahsil ettiği mal bedelini kendi ve Mudarib'in komisyon ve karını kestikten sonra kalan miktarı PYŞ’ye aktarır.

13) PYŞ, VKŞ'den tahsil ettiği tutarları portföylere aktarır.

\subsection{Ticaretin Finansmanı Banka Kurgusu}

Banka ile Restricted Wakala anlaşmasının yapılması ile bireysel portföy yönetimi çerçevesinde toplanan fonlar bankada açılan özel bir havuz hesabına aktarılıp belirtilen ticari işlemin finansmanı için mudaribe aktarılmaktadır. Fonlamanın kira sertifikası ihracı ile yapıldığı senaryoda yer alan VKŞ’nin görevini bu senaryoda banka üstlenmektedir.

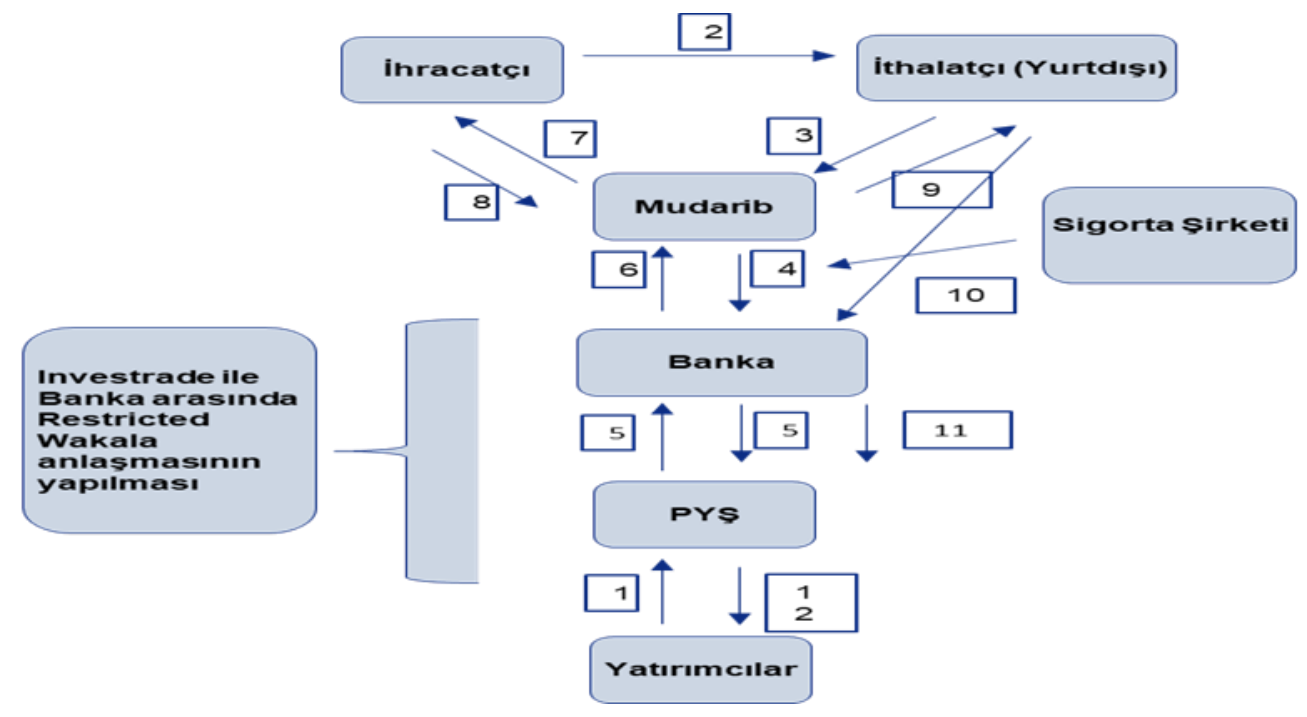

Şekil 8. Ticaretin finansmanı banka kurgusu işleyişi

1) PYŞ, bireysel portföy yönetimi çerçevesinde yatırımcılardan fon toplar. Ya da kuracağ fonlara \%10 oranında dahil eder.

2) İhracatçı firma ile ithalatçı firma malın satımı konusunda anlaşır. Ancak işlemin şeri kurallara uygun olması için mal ithalatçıya fatura kesilmez.

3) İthalatçı firma malın uygun olduğunu kontrol ettikten sonra "Buyer's Acceptance" belgesini yani malı alacağını vade sonunda parayı vereceğini belirten belgeyi Mudarib'e verir. 
4)Mudarib, "Buyer's Acceptance” belgesini ve alacağını sigortaladığına dair belgeyi Banka'ya verir.

5) Banka, Buyer's Acceptace ve alacağın sigortalandığına dair belgeyi inceledikten sonra PYŞ topladığı fonları Restricted Wakala sözleşmesi ile belirtilen ticari işlem için mudaribin kullanması adına bankada oluşturulan özel bir havuza yatırır. Saklamacı kuruluşa söz konusu Restricted Wakala sözleşmesi iletilecektir.

6) Banka PYŞ'den Restricted Wakala çerçevesinde aldığı fonu belirtilen ticari işlemin finansmanını sağlaması için mudaribe aktarır.

7) Mudarib, bankadan temin ettiği finansmanı ihracatçıdan malı satın almak için kullanır.

8) İhracatçı bedelini peşin tahsil ettikten sonra malın mülkiyeti mudaribe geçer.

9) Mudarib, bedelini vadesinde tahsil etmek üzere malı ithalatçıya satar.

10) İthalatçı vadesi gelince malın bedelini Restricted Wakala sözleşmesi çerçevesinde bankada açılan özel havuza aktarır.

11) Banka, ithalatçıdan tahsil ettiği mal bedelini kendi maliyeti ve mudaribin karı düşüldükten sonra PYŞ’ye aktarır.

12) PYŞ tahsil edilen bedeli yatırımcılara aktarır.

\subsection{Modelin Güçlü Yanları}

Ortalama vadesi 5 yıl olan USD bazlı sukuk ihraçlarının vadesi ticaretin finansmanı modeli ile birlikte 3, 6, 9 ve 12 aya kadar düşecektir. USD bazlı ihraçlarda vadenin azalması ve alacakların sigortalanmış olması kira sertifikalarının ikinci el piyasasında likiditenin önemli oranda artmasını sağlayacaktır. Artan likidite, kısalan vadeler ve USD bazlı yatırım araçlarının nispeten kısıtlı olması USD bazlı kira sertifikalarına olan talebin artmasına ve dolayısıyla ihraçların çoğalmasına sebebiyet verecektir.

Mudarib'in tek başına ulaşamayacağı sermaye piyasası kanalları fon temini için mudarib adına önemli bir kaynak olacaktır. Böylece büyüme potansiyeli bulunan ve ihracatı olan şirketler, bankalar nezdinde kredi limitleri dolmuş olsa bile ticaret finansmanı yapısı ile 
sermaye piyasalarından fon temin edebilecektir. Ticaretin finansmanı kurgusu ihracat yapan şirketlerin nakit akımlarını rahatlatacağı için Türkiye'nin ihracatını pozitif etkileyecektir.

Yurtdışı ve yurtiçi yatırımcılar için mevduatın haricinde USD bazlı önemli bir getiri oranına sahip olabilecek alternatif bir yatırım aracı doğmuş olacaktır. Bu ürüne portföy yönetim şirketlerinin borçlanma araçları fonları ile emeklilik fonlarının önemli oranda ilgi göstermesi kaçınılmazdır. 70 milyar TL'ye ulaşan emeklilik fonları pazarı potansiyel hakkında önemli ipuçları vermektedir.

Ticaretin finansmanı aracılığı ile fon kullanan ihracatçı şirketlerin maliyeti kredi maliyetlerinin aşağısına inecek ve fon sahipleri ise katılma paylarından ayrı olarak alacak sigortalı İslami bir üründe değerlendirebileceklerdir. Ticaret finansmanı modeli ile Türkiye riskinden bağımsız olarak yabancı yatırımcılardan fon sağlanması konusunda önemli avantajlar sağlanacaktır. Diğer bir ifade ile Türkiye'de finansman sıkıntısı yaşanması durumunda dahi yurtdışından bu ürün aracılığg ile fon temin etmek mümkün olacaktır. Vade sonunda alacağı ödeyecek kurum Avrupa'da kurulu bir şirkettir. Ayrıca dolar bazlı alacak için sigorta yapılmaktadır.

Bu ürün sadece ihracat yapan firmalar için değil aynı zamanda yurtiçinde ticaret yapan firmalar için de kurgulanabilir. Böylece yurtiçi ticaret yapan yerli firmaların dahi maliyetleri aşağı çekileceğinden hem istihdam hem de GSYH anlamında önemli katkıların doğması muhtemeldir. Bu şekilde zamanla Türkiye ihracatının önemli bir bölümünün fonlanması bankalardan bağımsız olarak gerçekleştirilebilir ve bu durum kriz zamanlarında çağrılan krediler nedeni sıkıntılar yaşayan firmalar için önemli bir avantaj olabilir.

Bütün ithalatçıların Avrupa'da olması alacakların ödenmeme riskini önemli oranda aşağı çekmektedir. Her ne kadar alacaklar sigortalanmış olsa da ithalatçıların borçlarını ödeyememesi faizlerin sıfıra yakın olduğu Avrupa bölgesinde dünyanın diğer bölgelerine nazaran çoğunlukla daha düşüktür.

Ticaret finansmanı kapsamında gerçekleştirilecek fonlamalar maksimum 250 bin USD'lik dilimler halinde gerçekleştirileceği için tek bir ithalatçının riskine katlanmak yerine riskler birden fazla ithalatçıya dağıtılmış olacaktır. Bu ürün ihracatı kolaylaştırdığı için ilerleyen dönemlerde siyasi iradenin ürünle alakalı teşvikler vermesi söz konusu olabilecektir. Ticaret finansmanı fonlamasına Katar İslam Bankası ve İslam Kalkınma Bankası gibi önemli banklalar tarafından icazet verilmiştir. Ticaret finansmanı kurgusu ile hali hazırda Katar İslam 
Bankası ve İslam Kalkınma Bankası gibi 13 bankanın içerisinde olduğu bir yapı üzerinden Türkiye'nin yıllık 1 milyar USD'lik ihracatı fonlanmaktadır. Raporumuzda anlatılan ürün ise bu yapıyı menkul kıymetleştirecek ve Türk sukuk piyasasına önemli bir güç katacaktır.

\subsection{Modelin Zayıf Yanları}

Modelin kurucusu ile yurtiçi banka ve Varlık Kiralama Şirketleri arasında anlaşmanın sağlanması gerekmektedir.

Sukuk modelinde Yönetime Dayalı Sukuk için kaynak kuruluşun yatırım yapılabilir not alması gerekmektedir. Buna ek olarak ürünün kendisinin yatırım yapılabilir not alması da yeterli olmaktadır. Ürünün sigortalı olması nedeniyle böyle bir problemin yaşanmaması beklenmektedir.

Ürünün Türkiye için yeni olması bazı iş ortaklarınca hemen kabul edilmesini engelleyebilir. Bununla birlikte modelin kurucusunun Türkiye'nin güçlü gruplarından olması, modelin 2 yıldır çalışıyor olması ve Ortadoğu'da 13 bankanın müşteri olması bu önyargıyı izale edebilir.

Ürün, ikinci metot olan sukuk modelinde dolar bazlı bir ürün olacağı için yurtiçinde yerleşik VKŞ’nin yurtdışı üzerinden bu ürünü ihraç etmesi ya da kote etmesi gerekecektir. Bu durumun önemli bir sorun yaratmayacağını beklemekteyiz.

Yurtdışı İslami bankalarca ürün fetva kurumlarından onay almasına rağmen yurtiçinde de benzer bir süreç gerekecektir.

Mevcut durumda ürünü kullanan bankalar için bu ürün Off the Balance olarak kaydedilmektedir. Türk bankaları ile ilk metotta çalışılmasında nasıl bir kayıt atılacağı araştırılmalıdır. İkinci metotta ise böyle bir problem yoktur.

Vadeler 1-3-6-9-12 ay olacağı için birden fazla sukuk ihracı gerekecektir. Bunun için SPK'dan tavan tespit edilmelidir. Sukuk modelinde bir problem gözükmezken Restricted Wakala modelinde bankanın operasyonel ve IT altyapısı kurması gerekebilir.

\section{SONUÇLAR}

Türk ekonomisi son yıllarda dünyanın en hızlı büyüyen ekonomilerinden biri olmuştur. Ancak büyümede iç tüketim modeli çalıştırılmış, ithalata dayalı ürünlerde tüketim artmış ve bu durum büyümeyle birlikte cari açıkta artışa ve dolarda önemli bir yükselişe sebep 
olmuştur. Büyüme ile gelen ithalat talebi dolarda önemli bir sıçramayı da beraberinde getirmiştir. İç tüketimin sağlanabilmesi için şirketler yüksek seviyede döviz kredisi kullanmış ve döviz açık pozisyonları nedeniyle dolardaki dalgalanma şirketlerde ve ekonomide riskleri önemli derecede artırmıştır. Bu durum Türk ekonomisi için orta uzun vadede reformların tamamlanıp ihracata dayalı büyümeyi elzem hale getirmektedir.

Türkiye'de ihracatçıların belirli kanallardan finansmanı sağlanmaktadır. Bu kanalların en önemlisi Eximbank ve bankalardır. Ancak büyüme potansiyeli olan ve banka limitleri dolmuş ihracatçılar için önerdiğimiz model bankacılık dışı ve şirketlerin borçlarını artırmadan finansmanını sağlamaktadır. Böylece şirketler ihracatları için banka dışı kanalı kullanarak borçlanma ya da hisse satışı da yapmamış olmaktadırlar.

Şirketlere ek olarak ürünün yatırımcılara hitap eden yanları vardır. Türkiye'de sukuklar henüz olması gerektiği kadar çeşitliliğe ve derinliğe sahip değildir. Sukuklar arasında dolar bazlı sukuklar ise çok daha nadir ihraç edilmektedir. Dolar bazlı sukuklarda ise vade 5 yıla kadar çıkmakta ve bu durum likiditeyi oldukça azaltmaktadır. Modelimiz sukuk piyasasında önemli bir hacim artışı getireceği gibi, dolar bazlı sukuklarda vadeyi kısaltacak ve sigortalı olması nedeniyle ikinci elde likiditeyi önemli oranda artıracaktır.

Modelimizin son faydası ise uluslararası yatırımların Türkiye'ye akışını hızlandırması olarak tanımlanabilir. Ticaretin finansmanı Ortadoğu'da sukuk modeli yerine Bankacılık özel havuz modeli üzerinden çalışmaktadır. Ancak bu modelde yatırımcılar vade sonuna kadar beklemektedir. Sukuk modelinin devreye girmesi halinde SPK'nın güven ve kontrolünde yapılacak bir ihraçta ürün ikincil piyasaya da sahip olacak ve likiditesi artacaktır. Ürünün likiditesi ve SPK güveni ile birlikte Ortadoğu'daki mevcut yatırımcılar için sukuk modeli banka modelinden daha cazip olacağı için Türkiye'ye körfez bölgesinden önemli seviyede yatırımın Türkiye'ye gelmesi sağlanabilir.

Modelin en büyük zorluğu mevcut kurulu düzende yenilikçi ürüne karşı dirençli olabilecek kurumlar ve mevzuatın güncellenme ihtiyacı olacaktır.

\section{REFERENCES / KAYNAKLAR}

Abdul Aziz, R. \& Gintzburger, A.-S. (2009). Equity-Based, Asset-Based and Asset-Backed Transactional Structures in Shari'a-Compliant Financing: Reflections on the Current Financial Crisis. Economic Papers, 270278. 
Beck, T., Demirguc-Kunt, A. \& Levine, R. (2005). SMEs, Growth and Poverty. Journal of Economic Growth, 199-229.

Cravoy, T., Gourlayy, A. \& Beckery, B. (2012). SMEs and Regional Economic Growth in Brazil. Small Bus Econ, 217-230.

Gundogdu, A. (2016). Exploring Novel Islamic Finance Methods in Support of OIC Exports. Journal of Islamic Accounting and Business Research, 78-92.

Gundogdu, A. \& Dogan, E. (2014). Two-step Murabaha in Stock Exchange As An Alternative to Commodity Murabaha for Liquidity Management. International Journal of Financial Services Management, 268-285.

Iqbal, M. \& Llewellyn, D. (2000). Islamic Banking and Finance: New Perspective on Profit Sharing and Risk. Cheltenham: Edward Elgar Publishing, Ltd.

Iqbal, Z. \& Mirakhor, A. (2006). An Introduction to Islamic Finance-Theory and Practice. Hoboken, New Jersey: Wiley Finance Editions, John Wiley \& Sons, Inc.

Iqbal, Z. \& Tsubota, H. (2006). Emerging Islamic Capital Markets. Islamic Finance Review, 5-11.

Rocha, R., Farazi, S., Khouri, D. \& Pearce, D. (2011). The Status of Bank Lending to SMEs in the Middle East and North Africa Region. Results of a Joint Survey of the Union of Arab Bank and the World Bank, Policy Research Working Paper 5607.

Singh, H. (2009). Islamic Hanks May Not Be Insulated from ‘Aftershocks. The Malaysian Reserve, Available at: http://islamicfinanceasia.blogspot.com/2009/03/islamic-banks-may-not-be-insulated-from. 